\title{
Faculty Perspectives in Saudi Arabia Pertaining to Attributes of Successful Universities and Future Learning Environments
}

\author{
Ibrahim Kutbi ${ }^{1}$ \& Khairuddin Hashim ${ }^{1}$ \\ ${ }^{1}$ Center for Strategic Studies, King Abdulaziz University, Saudi Arabia \\ Correspondence: Khairuddin Hashim, Center for Strategic Studies, King Abdulaziz University, Jeddah 21589, Saudi \\ Arabia.
}

Received: November 24, 2016

Accepted: October 1, 2017

Online Published: October 12, 2017

doi:10.5430/ijhe.v6n5p95

URL: https://doi.org/10.5430/ijhe.v6n5p95

\begin{abstract}
Universities face the challenge of being relevant. This study investigates respondents' perspectives pertaining to attributes of successful universities and future learning environments. Data were collected using a specially designed survey during the 2016 academic year. The sample size was 518 King Abdulaziz University (KAU) academics. The results highlight critical attributes, management elements and dominant pedagogical and technological trends. The paper also reports significant differences between gender, discipline and years of experience sub-groups. The findings identify key themes, trends and perspectives that can be used as foundation for more in-depth research to discern possible strategies towards achieving success.
\end{abstract}

Keywords: Successful university, Learning environment, Faculty perspective, Gender difference, Discipline difference, Higher education

\section{Introduction}

Universities should be changing from a place where knowledge outside the classroom is reported and transformed to students, to one where students themselves directly experience having a hand in creating knowledge (King \& Sen, 2013). The modern university should serve its communities and provide highly skilled innovative manpower appropriate for current and future global needs.

With the rapid changes in requirements, universities face the challenge of being relevant. There is need to identify the attributes of successful universities and future learning environments for universities to prepare themselves towards achieving success. Educators need to look beyond what they presently have, identify future ideas and put them into practice.

We are living in a time of exponential change. Education is shifting from the traditional classroom approach to technology-driven methods that tailor learning to an individual's needs. The ultimate challenge is to customize pedagogical approaches to fit the learning styles of individuals. Learning has to be continuous, supporting life-long education.

The major contribution of the study lies in identifying factors, perceptions and perspectives pertaining to successful universities and future learning environments that can be used as a foundation for more in-depth research to discern possible strategies towards achieving success. Given the present scarcity of data, the data gathered provide a valuable source of information as they offer a deeper insight into attributes and factors.

\section{Literature Review}

\subsection{Successful Universities}

Success depends on institutions finding ways of getting a lot of relatively small decisions right over a long period. This is a blueprint for a holistic management style and for understanding and attending all the different aspects of management that can create a momentum in which success reinforces success (Shattock, 2010).

Three factors distinguish top international universities from their competitors (Salmi, 2009). The first is presence of a high concentration of talented teachers, researchers and students. These institutions focus on attracting the most talented people, no matter where they come from, and open themselves to new ideas and approaches. 
The second factor that sets top universities apart are their sizable budgets. The third factor of success is a combination of freedom, autonomy and leadership. World-class universities thrive in an environment that fosters competitiveness, unrestrained scientific inquiry, critical thinking, innovation and creativity to manage their resources efficiently and quickly respond to the demands of a rapidly changing global market.

A World Bank report (Russel Group, 2012) suggests that there are 3 inter-related critical success factors which distinguish a world class university:

- A high concentration of talent (both faculty and students);

- Sufficient resources to provide an extensive and comprehensive learning environment and a rich environment for advance research;

- Favorable governance to encourage autonomy, strategic vision, innovation, efficient resource management and flexibility.

The bottom line here is not that low and middle-income countries should abandon dreams to set up their own world-class universities. Instead, they ought to understand that there are trade-offs involved.

\subsection{Future Learning Environments}

The field of higher education is undergoing a revolution. New technologies and new approaches to learning are altering the way educational programs are delivered and are changing the way we learn (Knowledge@Wharton, 2014). Successful implementation of flipped classroom approach has been achieved (Pearson, 2013a; Pearson, 2013b). This could be a major future trend.

Technology has to be used to customize the learning experience and move towards personalized learning to suit different individual needs. Basic characteristics of a good teaching and learning environment remain and include the following:

- $\quad$ supportive and productive;

- promotes independence and self-motivation;

- develops cognitive skill levels.

Personal Learning Environments (PLEs) are being put forward as a new approach to the development of e-learning tools that are no longer focused on integrated learning platforms such as Virtual Learning Environments (VLEs). In contrast, these PLEs are made-up of a collection of loosely coupled tools, including Web 2.0 technologies, used for working, learning, reflection and collaboration with others (Attwell, 2008).

\section{Methodology}

In this study both primary and secondary sources of data were used. The primary data for this research study were collected through interviews and a survey. Survey data were collected through a questionnaire from randomly selected respondents representing a sample of academics at King Abdulaziz University (KAU). The survey included a total of $518 \mathrm{KAU}$ academics from various faculties/colleges. The target respondents represented a homogeneous mix to sufficiently preserve optimal diversity within the collected data required for subsequent analysis.

The questionnaire was pre-tested and revised by several senior university faculty members, who made modifications to enhance clarity. It was then pilot tested. The questionnaire was divided into three sections. In the first section, respondents were requested to respond to demographic questions about their gender, faculty discipline (arts/science) and working experience. The second section provided explicit questions on attributes of successful universities covering the following aspects:

- Critical general attributes;

- Key domains/categories;

- Critical management elements.

The third section covered explicit questions on attributes of future learning environments covering the following aspects:

- Dominant pedagogical trends over the next 10 years;

- Dominant technological trends over the next 10 years;

- Critical factors in providing a good learning environment. 
The raw data from the survey were then coded and entered into the statistical system. The data were explored both for their descriptive statistics (i.e. calculation of percentage distributions, frequency distributions, calculations of means and standard deviation) and inferential statistics (i.e. level of significance) (Sheskin, 2011). Results were analyzed and summarized, in order to draw conclusions and make recommendation.

\section{Results and Discussion}

A total of $518 \mathrm{KAU}$ academics participated in the survey. The total sample size meant an acceptable error of $\pm 4 \%$ at 95 percent confidence level for KAU population. The demographic breakdown by faculty discipline, gender and working experience is given in Table 1.

Table 1. Demographic Breakdown

\begin{tabular}{|c|c|c|c|c|c|c|c|c|c|c|c|}
\hline \multicolumn{4}{|c|}{ Gender } & \multicolumn{4}{|c|}{ Faculty Discipline Type } & \multicolumn{3}{|c|}{$\begin{array}{l}\text { Years of working experience in university } \\
\text { education }\end{array}$} & \multirow[t]{3}{*}{ Total } \\
\hline Male & & Female & & Arts & & Scienc & & Less than 5 years & 5 Year & or more & \\
\hline Count & $\%$ & Count & $\%$ & Count & $\%$ & Count & $\%$ & Count & Count & $\%$ & \\
\hline 213 & 41.1 & 305 & 58.9 & 233 & 45.0 & 285 & 55.0 & 23.4 & 397 & 76.6 & 518 \\
\hline
\end{tabular}

Data regarding perspectives on the items in the survey were collected using a five-point Likert level of agreement scale. The mean analysis table is given in Table 2.

Table 2. Mean analysis table

\begin{tabular}{ll}
\hline Range & Mean Analysis \\
\hline 1 to 1.80 & Strongly Disagree \\
1.81 to 2.60 & Disagree \\
2.61 to 3.40 & Unsure \\
3.41 to 4.20 & Agree \\
4.21 to 5 & Strongly Agree \\
\hline
\end{tabular}

In this study, to test for normality, the Shapiro-Wilk test is used. A p-value of less than 0.05 under the Shapiro-Wilk test indicates that a sample is not normally distributed. In such a case, the Mann-Whitney test is used for identifying significant differences between the responses of two independent groups (Sheskin, 2011). A p value of less than 0.05 indicates that there is a significant difference between the responses of the two groups.

\subsection{Overall Responses}

This section gives the outcome of data analysis on attributes of successful universities and future learning environments. Table 3 highlights items in decreasing order of means for section on critical attributes for a university to be successful. Analysis of the means of responses indicates that item 'appropriate governance' is considered to be the most critical attribute for a university to be successful whereas item 'academically successful staff taking role in governance and management' is considered the least critical attribute for a university to be successful. The outcome of survey is in line with the World Bank report (Russel Group, 2012) which identifies the top three critical attributes in Table 3 as critical success factors.

Table 3. Critical attributes for a university to be successful

\begin{tabular}{lll}
\hline Item & Mean & SD \\
\hline $\begin{array}{l}\text { Appropriate governance (leadership, strategic } \\
\text { vision, innovation and flexibility) }\end{array}$ & 4.27 & 0.920 \\
$\begin{array}{l}\text { Concentration of excellent faculty members } \\
\text { and excellent students }\end{array}$ & 4.21 & 0.832 \\
$\begin{array}{l}\text { Abundant resources (funding, teaching labs, } \\
\text { research labs, etc.) }\end{array}$ & 4.19 & 0.933 \\
$\begin{array}{l}\text { Academically successful staff taking role in } \\
\text { governance and management }\end{array}$ & 4.07 & 0.937 \\
\hline
\end{tabular}


Table 4 highlights items in decreasing order of means for the section on key domains/categories of successful universities. Analysis of the means of responses indicates that item 'leading-edge research and publication' is considered to be the most preferred category of successful universities whereas item 'return of investment' is considered the least preferred category.

Table 4. Key domains/categories of successful universities

\begin{tabular}{lll}
\hline Item & Mean & SD \\
\hline Leading-edge research and publication & 4.27 & 0.824 \\
Innovativeness (e.g. programs, graduates, research products, patents) & 4.21 & 0.825 \\
Contribution to communities & 4.2 & 0.837 \\
Graduate employability & 4.13 & 0.853 \\
Graduate entrepreneurship & 3.96 & 0.818 \\
Return of investment & 3.71 & 0.873 \\
\hline
\end{tabular}

Table 5 highlights items in decreasing order of means for the section on critical management elements for successful universities. Analysis of the means indicates that item 'clear vision' is considered to be the most critical management element for successful universities whereas item 'decisiveness' is considered the least critical management element.

Table 5. Critical management elements for successful universities

\begin{tabular}{lll}
\hline Item & Mean & SD \\
\hline Clear vision & 4.48 & 0.817 \\
Continuous improvement & 4.46 & 0.770 \\
Flexible and efficient management & 4.41 & 0.817 \\
Collaboration & 4.36 & 0.829 \\
Effective fund management & 4.32 & 0.811 \\
Inspired leader & 4.32 & 0.855 \\
Innovativeness & 4.23 & 0.830 \\
Adaptability & 4.20 & 0.810 \\
Accountability & 4.20 & 0.859 \\
Academic freedom & 4.13 & 0.896 \\
Institutional autonomy & 4.08 & 0.832 \\
Decisiveness & 4.08 & 0.909 \\
\hline
\end{tabular}

Table 6 highlights items in decreasing order of means for the section on dominant pedagogical trends within the next 10 years. Analysis of the means indicates that item 'problem based learning' is considered to be the most dominant pedagogical trend in the next 10 years whereas item 'online learning' is considered the least dominant pedagogical trend.

Table 6. Dominant pedagogical trends within the next 10 years

\begin{tabular}{lll}
\hline Item & Mean & SD \\
\hline Problem-based learning & 4.13 & 0.774 \\
Simulation-based learning & 4.01 & 0.826 \\
Blended learning & 3.95 & 0.870 \\
Social learning using social media & 3.79 & 0.936 \\
Game-based learning & 3.70 & 0.871 \\
Flipped Learning & 3.69 & 0.921 \\
Online learning & 3.54 & 1.013 \\
\hline
\end{tabular}


Item 'social learning using social media' is within the top four dominant pedagogical trends. An article (McLoughlin \& Lee, 2008) supports the notion that social software tools offer opportunities to move away from the last century's highly centralized, industrial model of learning and toward individual learner empowerment through designs that focus on collaborative and networked interaction.

However, item 'game-based learning' is not within the top four dominant trends. Market research firm Ambient Insight includes game-based learning among the eight types of pedagogically-defined learning products (Epper, Derryberry \& Jackson, 2012). The New Media Consortium's NMC Horizon Report: 2012 Higher Education Edition puts the time-to-adoption horizon for game-based learning at 2 to 3 years.

It is also interesting to note that item 'flipped learning' is not within the top four dominant pedagogical trends. An article (Flipped Learning Network, 2014) documents that almost three-quarters of over 180,000 middle and high school students who participated in the Speak Up 2013 surveys agree that flipped learning would be a good way for them to learn, with 32 percent of those students strongly agreeing.

Table 7 highlights items in decreasing order of means for the section on dominant technological trends within the next 10 years. Analysis of the means indicates that item 'learning analytics' is considered to be the most dominant technological trend in the next 10 years whereas item 'electronic edu-gaming' is considered the least dominant technological trend.

Table 7. Dominant technological trends within the next 10 years

\begin{tabular}{lll}
\hline Item & Mean & SD \\
\hline Learning analytics & 3.95 & 0.807 \\
Electronic simulation & 3.95 & 0.842 \\
Personalised learning environment & 3.93 & 0.796 \\
Mobile and ubiquitous learning environment & 3.89 & 0.882 \\
Augmented reality & 3.87 & 0.775 \\
Electronic edu-gaming & 3.66 & 0.907 \\
\hline
\end{tabular}

Table 8 highlights items in decreasing order of means for section on critical factors in providing good learning environments. Analysis of the means indicates that item 'trained teachers' is considered to be the most critical factor in providing good learning environments whereas item 'universal design' is considered the least critical factor.

Table 8. Critical factors in providing good learning environments

\begin{tabular}{lll}
\hline Item & Mean & SD \\
\hline Trained teachers & 4.44 & 0.764 \\
Technology upgrades of learning environments & 4.42 & 0.751 \\
Technical support for teachers & 4.40 & 0.739 \\
Appropriate learning and teaching facilities & 4.38 & 0.714 \\
Learning support & 4.33 & 0.744 \\
Meeting needs of new generation - Approach and tools & 4.31 & 0.762 \\
Latest information and skill requirements & 4.25 & 0.790 \\
Flexible/Multiple delivery modes & 4.22 & 0.769 \\
Learning space design & 4.08 & 0.742 \\
Universal design & 3.95 & 0.840 \\
\hline
\end{tabular}

It is interesting to note that providing flexibility in learning and addressing needs of the new generation and skills requirements are not within the top five critical factors in providing good learning environments. Perspectives of top critical factors in providing good learning environments revolve around rudimentary concerns pertaining to training and technical support for teachers; and learning and teaching facilities (including technology upgrades). 


\subsection{Gender Comparison}

Studies (Bönte, 2015; Croson \& Gneezy, 2009) have indicated that there are gender differences in preferences and abilities. As such, it is of interest to investigate possible existence of gender differences pertaining to the study. Shapiro-Wilk test conducted indicates that the samples are not normally distributed. Therefore, Mann-Whitney test is used to test whether significant differences exist between the responses of the male and female sub-groups.

Mann Whitney results indicate the following:

- There is a significant difference for item 'concentration of excellent faculty members and excellent students' under the section on critical attributes for a university to be successful.

- There is a significant difference for each of the following items under the section on dominant pedagogical trends within the next 10 years:
○ Blended learning;
- Flipped learning;
○ Online learning;
- Game-based learning;
- Social learning using social media;
- Simulation-based learning.

- There is a significant difference for each of the following items under the section on dominant technological trends within the next 10 years:

- Mobile and ubiquitous learning;

- Personalized learning;

○ Augmented reality;

- Electronic edu-gaming.

- There is a significant difference for each of the following items under the section on critical factors in providing good learning environments:

- Universal design;

○ Learning space design;

- Meeting needs of new generation;

- Flexible/Multiple delivery modes;

$\circ \quad$ Learning support;

- Technical support for teachers.

\subsection{Discipline Comparison}

In the context of differences between disciplines, studies (Furnham, Batey, Booth, Patela \& Lozinskaya, 2011; Hartley \& Greggs, 1997; Williamson, 2011) have indicated that there are differences in preferences and abilities of arts and science students pertaining to matters such as learning and thinking styles. Likewise, academics from the two disciplines are assumed to have similar characteristics. As such, it is of interest to investigate possible existence of discipline differences pertaining to the study. Shapiro-Wilk test conducted indicates that the samples are not normally distributed. Therefore, Mann-Whitney test is used to test whether significant differences exist between the responses of the arts and science sub-groups.

Mann Whitney results indicate the following:

- There is a significant difference for item 'continuous improvement' under the section on critical management elements for successful universities.

- There is a significant difference for each of the following items under the section on dominant pedagogical trends within the next 10 years:

- Blended learning;

- Flipped learning; 
○ Online learning;

- Game-based learning;

- Social learning using social media;

- Simulation-based learning.

- There is a significant difference for item 'learning analytics' under the section on dominant technological trends within the next 10 years.

\subsection{Number of Years Working Experience Comparison}

Shapiro-Wilk test conducted indicates that the samples are not normally distributed. Therefore, Mann-Whitney test is used to test whether significant differences exist between the responses of the two working experience sub-groups (less than 5 years and 5 years or more).

Mann Whitney results indicate the following:

- There is a significant difference for item 'academically successful staff taking role in governance and management' under the section on critical attributes for a university to be successful.

- There is a significant difference for items 'graduate employability' and 'contribution to communities' under the section on key domains/categories of successful universities.

- There is a significant difference for each of the following items under the section on critical management elements for successful universities:

○ Flexible and efficient management;

○ Academic freedom;

○ Innovativeness;

○ Accountability;

○ Decisiveness.

- There is a significant difference for item 'simulation-based learning' in the section on dominant pedagogical trends within the next 10 years.

\section{Conclusion}

The survey compiled KAU academics' perspectives pertaining to attributes of successful universities and future learning environments. To begin with, the top three critical attributes for successful universities in decreasing order of means are: (i) appropriate governance (leadership, strategic vision, innovation and flexibility), (ii) concentration of excellent faculty members and excellent students and (iii) abundant resources (funding, teaching labs, research labs, etc.).

Subsequently, the top four categories of successful universities in decreasing order of means are: (i) leading-edge research and publication, (ii) innovativeness (e.g. programs, graduates, research products, patents), (iii) contribution to communities and (iv) graduate employability. Regarding management elements, the top six critical management elements for successful universities in decreasing order of means are: (i) clear vision, (ii) continuous improvement, (iii) flexible and efficient management, (iv) collaboration, (v) effective fund management and (vi) inspired leader.

Pertaining to pedagogical trends, the top four dominant pedagogical trends within the next 10 years listed in decreasing order of means are: (i) problem-based learning, (ii) simulation-based learning, (iii) blended learning and (iv) social learning using social media. Relating to technological trends, the top four dominant technological trends within the next 10 years in decreasing order of means are: (i) learning analytics, (ii) electronic simulation, (iii) personalised learning environment, (iv) mobile and ubiquitous learning environment and (v) augmented reality.

With reference to factors pertaining to provision of good learning environments, the top five critical factors in decreasing order of means are: (i) trained teachers, (ii) technology upgrades of learning environments, (iii) technical support for teachers, (iv) appropriate learning and teaching facilities and (v) learning support.

Comparisons between gender, discipline and years of experience sub-groups indicate that there exist some significant differences between the sub-groups. 
These findings can be used as a foundation for more in-depth research to discern possible strategies towards achieving successful university status and in equipping universities with learning and teaching environments of the future.

\section{References}

Attwell, G. (2008). Social Software, Personal Learning Environments and the Future of Teaching and Learning. Retrieved from http://www.pontydysgu.org/wp-content/uploads/2008/09/portplesfin.doc

Bönte, W. (2015) Gender differences in competitive preferences: New cross-country empirical evidence. Applied Economics Letters, 22(1), 71-75. https://doi.org/10.1080/13504851.2014.927560

Croson, R., \& Gneezy, U. (2009). Gender Differences in Preferences. Journal of Economic Literature 2009, 47(2), 1-27. https://doi.org/10.1257/jel.47.2.448

Epper, R. M., Derryberry, A., \& Jackson, S. (2012). Game-Based Learning: Developing an Institutional Strategy. Research Bulletin. Boulder, CO: EDUCAUSE Center for Applied Research.

Flipped Learning Network (2013). Speak Up 2013 National Research Project Findings A second year review of flipped learning.

Retrieved fromhttp://flippedlearning.org/cms/lib07/VA01923112/Centricity/Domain/41/Speak\%20Up\%202013\%20Surve y\%20Results\%20Flipped\%20Learning\%20Network.pdf

Fu, E., \& Hsia, T. (2014).Universities and Entrepreneurial Ecosystems: Elements of the Stanford-Silicon Valley Success, Kauffman $\quad$ Fellows $\quad$ Report, $\quad$ Vol. $5 . \quad$ Retrieved from .http://www.kauffmanfellows.org/journal_posts/universities-and-entrepreneurial-ecosystems-stanford-silic on-valley-success/

Furnham, A., Batey, M., Booth, T. W., Patela, V., \& Lozinskaya, D. (2011). Individual difference predictors of creativity in Art and Science students. Thinking Skills and Creativity, 6(2), 114-121. https://doi.org/10.1016/j.tsc.2011.01.006

Hartley, J., \& Greggs, M. (1997). Divergent thinking in arts and science students: Contrary Imaginations at Keele revisited. Studies in Higher Education, 22(1), 93-97. https://doi.org/10.1080/03075079712331381161

http://scholarsarchive.jwu.edu/cgi/viewcontent.cgi?article=1004\&context=mba_student

King, G., \& Sen, M. 2013. The Troubled Future of Colleges and Universities (With Comments from Five Scholar-Administrators). PS: Political Science and Politics, 1(46), 81--113. https://doi.org/10.1017/S1049096512001771

Knowledge@Wharton (2014). How Innovation and the 'Reimagined' Classroom will Change Learning. Retrieved from http://knowledge.wharton.upenn.edu/article/innovation-reimagined-classroom-will-change-learning/

McLoughlin, C., \& Lee, M.J.W. (2008). Future Learning Landscapes: Transforming Pedagogy through Social Software. Innovate: Journal of Online Education, 4(5).

Pearson. (2013a). Flipped Learning Model Increases Student Engagement and Performance. Retrieved from http://assets.pearsonschool.com/asset_mgr/current/201320/Byron_standalone_casestudy.pdf.

Pearson. (2013b). Flipped Learning Model Dramatically Improves Course Pass Rate for At-Risk Students. Retrieved from http://assets.pearsonschool.com/asset_mgr/current/201317/Clintondale_casestudy.pdf

Russel Group. (2012). Jewels in the Crown: The Importance and Characteristics of UK World-Class Universities. Retrieved from http://russellgroup.org/JewelsInTheCrown.pdf

Salmi, J. (2009). What Makes A University Great? Retrieved from http://www.forbes.com/2009/08/10/world-class-best-university-ranking-world-bank-opinions-colleges-salmi.ht $\mathrm{ml}$

Shattock, M. (2010). Managing Successful Universities (2nded.). Maidenhead: McGraw-Hill, Society for Research into Higher Education \& Open University Press.

Sheskin, D. J. (2011). Handbook of Parametric and Nonparametric Statistical Procedures. Boca Raton, Florida: Chapman and Hall/CRC.

Williamson, P. K. (2011). The creative problem solving skills of arts and science students-The two cultures debate revisited. Thinking Skills and Creativity, 6(1), 31-43. https://doi.org/10.1016/j.tsc.2010.08.001 